\title{
The Frequency of Adverse Effects and Early Outcomes of Cardiac Catheterization in Children
}

\author{
Ghaderian Mehdi ${ }^{1 *}$, Shoja Mohammad², Shoja Mohsen ${ }^{3}$, Sabri Mohammad Reza ${ }^{1}$ and Ahmadi Ali Reza ${ }^{1}$ \\ ${ }^{1}$ Pediatric Interventional Cardiologist, Isfahan University of Medical Science, Iran \\ ${ }^{2}$ Pediatric Cardiologist, Isfahan University of Medical Science, Iran \\ ${ }^{3}$ Epidemiologist in Bojnord University of Medical Science, Iran
}

Submission: November 24, 2017; Published: December 18, 2017

*Corresponding author: Ghaderian Mehdi, Pediatric Interventional Cardiologist, Isfahan University of Medical Science, Iran, Tel: +989131004787

; Email: ghader_45@yahoo.co.uk

\begin{abstract}
Diagnostic and interventional catheterization especially is invasive procedures that naturally can occur with risks and side effects for patients. This article examines the prevalence and detection of unpleasant side effects and early outcomes occurred deals by angiography. The study performed in patients undergoing angiography in Isfahan University of Medical Sciences in children department at one year. 372 patients, including 185 men and 187 women underwent angiography, which were 172 diagnostic angiography and 200 were interventional angiography. Among these patients, 105 had cyanotic heart disease, and 267 patients were non-cyanotic. Of the patients, 18 patients (5\%) had unpleasant side effects or bad early outcome during angiography include (emboli of breaking wires and interventional devices in the body, death, drug allergies, fever and bleeding and need to blood transfusion), 160 patients (43\%) had transient arrhythmias were less important during angiography and $15(4.5 \%)$ also need medication to stop the arrhythmia or led to complication in the patients.
\end{abstract}

Keywords: Adverse event; Early outcome; Cardiac catheterization

\section{Introduction}

New non-invasive procedures such as echocardiography and various imaging modalities although had special place in recognition of congenital heart disease, but cardiac angiography, as a practical method at inefficiency of described methods, however show the hidden aspects of cardiac disease [1,2]. Especially in recent years the trend to perform some interventional cardiac angiography for repair of cardiac lesions, therefore led more complications occurred during the procedures [2]. Assess the consequences of catheterization, the side effects and deaths in heart centers and laboratories catheterization is important for managers [3]. Given the importance of the adverse effects and risks during angiography or later happen to patients, this article examines the prevalence and detection of these complications occurred in subjects while generating greater awareness and preparation of the medical team, equipment and medications, for prevention and early treatment in patients provide these problems [4].

\section{Methods}

The study was retrospective and cross-sectional that all patients in Isfahan Chamran martyr hospital underwent angiography by pediatric cardiologist were selected. Inclusion criteria included patients undergoing angiography by pediatric service in children department. Exclusion criteria included patients undergoing angiography in the pediatric service that their file documents were incomplete. Data obtained using a selfmade checklist of records in the case participants (Information such as the type of angiography (diagnostic or interventional), unpleasant complications and early outcomes occurred, the type of arrhythmia and the length of it, the need for medication or electroconvulsive to terminate the arrhythmia, the patient's age and other demographic information needed) were extracted. Ethical considerations such as confidentiality and the need to disseminate the results of the study participants as a whole and not the individual, was considered. The data from the study using descriptive statistics and independent t test, chi-square and Fisher exact test were analyzed with statistical software SPSS18.

\section{Results}

Of the 372 participants in the study who had undergone angiography, 185 cases were male. 113 children were under one year, 134 people between one to six years and 125 were above 6 
years of age. 28 patients had weight below $5 \mathrm{~kg}, 124$ had $5-10 \mathrm{~kg}$ and 220 were over $10 \mathrm{~kg}$. Angiography in 172 patients $(46 \%)$ of subjects in the study had been done for diagnostic reasons and in 200 patients intervention was done. In 352 cases (95\%) the time of angiography was 30 to 60 minutes and under half an hour in 9 subjects and in 11 patients took more than one hour. 105 patients (28\%) with cyanotic heart disease and 267 patients (72\%) had non-cyanotic heart disease of the patients, 18 patients $(5 \%)$ had unpleasant side effects or bad early outcome during angiography include (emboli of breaking wires and interventional devices in the body, death, drug allergies, fever and bleeding and need to blood transfusion). Among these patients we had two cases of embolism and device transposition.

A 40 days patient with pulmonary valve atresia and tricuspid atresia admitted for PDA stent (interventional angiography) that stent was moved from its site (Figure 1) and patient transported to the operation room for emergency BT shunt and stent was taken out.

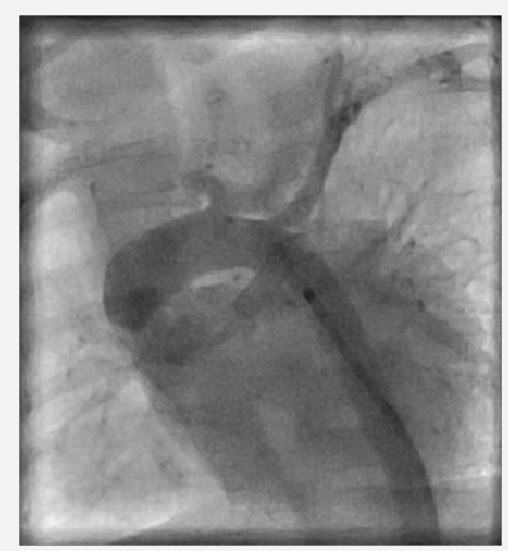

Figure 1: Lateral view of patient with pulmonary and tricuspid atresia that during interventional angiography PDA was stented to supply PA flow, but stent displaced in to aorta and lead to coarctation in descending aorta.

A 10-years-old patient with malignant problems underlying the CVC in the SVC, his CVC was broken during attempt to removal it. Angiography were done to leave it that CVC during removal breaks and half of it removed and with Snare remaining half retrieved into sheet again and drawn into the sheet and exited. An 8.5-month-old patient was diagnosed with cardiomyopathy due to ALCAPA who have arrhythmia during cardiac catheterization and cardiac arrest that did not respond to resuscitation efforts and died. And cases of drug allergies and severe bleeding and hematoma and ecchymosis were leading to injection, transfusion of blood products were. Another patient had five months old that after deployment of the Amplatzer in PDA, embolism occurred into abdominal aortic bifurcation that by Bioptum the device was removed (Figure 2). Of total 372 cases of patients under study, 160 patients $(43 \%)$ had transient arrhythmias were less important during angiography and $15(4.5 \%)$ also need medication to stop the arrhythmia or led to complication in the patient.

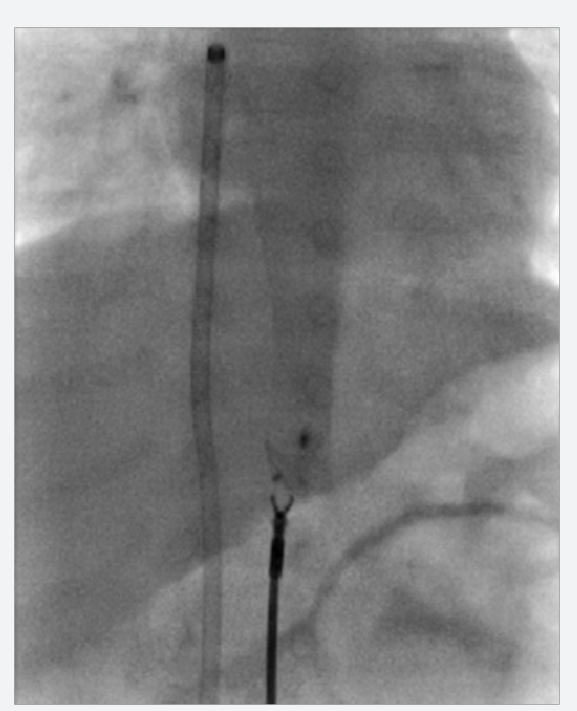

Figure 2: AP view angiography of abdominal aorta in patient with PDA that after deployment of device in PDA, amplatzer was embolied and in abdominal aorta caught with bioptum and then retrieved into the sheet and removed. 


\section{Discussion}

Mr. Phillips et al. [5] investigated the adverse effects occurred among the 903 patients at the years between 2005 and 2007 underwent angiography that 42 patients aged less than 18 years. 455 patients were female and the average age was 29 years, $51 \%$ of patients undergoing diagnostic angiography and interventional were $43 \%$ and $6 \%$ for biopsy were done angiography. Dose of contrast agent used was $1.9 \mathrm{cc}$ per $\mathrm{kg}$, $89 \%$ had no complication, and 102 patients had complications. Death complication no happened.

Odegard et al. [6] in a study of 7289 patients who underwent angiography for 5 years between 2004 and 2009, the incidence of cardiac arrest were examined. And their definition of cardiac arrest cases were included, cases leading to cardiac massage to rescue the patient. Among these were 70 patients with cardiac arrest, of which $69 \%$ were successful resuscitation with massage and $26 \%$ were in need of ECMO machine and 4 patients didn't resuscitated. Sudden arrhythmia in $54 \%$ of cases was the cause of cardiac arrest. $71 \%$ took less than 11 minutes of resuscitation.

Mah et al. [7] in a study of 6183 patients who had undergone angiography within six years of the study, the incidence of heart block among these patients was 2.1\% (135 patients had heart block). The patients' average weight was $15 \mathrm{~kg}, 29 \%$ of them were under one year old. Among the patients, $72 \%$ had complex cardiac disease and angiography time over two hours was identified as one of the risk factors for heart block. Heart block in $97 \%$ of these patients recovered within a week, and another required pacemakers. Our study is different from previous studies because we obtained all of the adverse events and the early outcomes of angiography in this study, but in general the final results are same together.

\section{Conclusion}

According to the more interventional angiography in the patients recently, the risk of side effects can be significant, the medical team should be familiar with the effects of the necessary tools and medications and blood products that needed to treat these complications to reduce the incidence of morbidity and mortality in patients [8-13].

\section{References}

1. Lee KE, Seo YJ, Kim GB, An HS, Song YH, et al. (2016) Complications of cardiac catheterization in structural heart disease. Korean Circ J 46(2): 246-255.

2. Yilmazer MM, Ustyol A, Güven B, Oner T, Demirpençe S, et al. (2012) Complications of cardiac catheterization in pediatric patients: a single center experience. Turk J Pediatr 54(5): 478-485.

3. Huang YC, Chang JS, Lai YC, Li PC (2009) Importance of prevention and early intervention of adverse events in pediatric cardiac catheterization: a review of three years of experience. Pediatr Neonatol 50(6): 280-286.

4. King MA, Garrison MM, Vavilala MS, Zimmerman JJ, Rivara FP (2008) Complications associated with arterial catheterization in children. Pediatr Crit Care Med 9(4): 367-371.

5. Phillips BL, Cabalka AK, Hagler DJ, Bailey KR, Cetta F (2010) Procedural complications during congenital cardiac catheterization. Congenit Heart Dis 5(2): 118-123.

6. Odegard KC, Bergersen L, Thiagarajan R, Clark L, Shukla A, et al. (2014) The frequency of cardiac arrests in patients with congenital heart disease undergoing cardiac catheterization. Anesth Analg 118(1): 175182.

7. Mah DY, Porras D, Bergersen L, Marshall AC, Walsh EP, et al. (2014) Incidence of and risk factors for catheterization-induced complete heart block in the pediatric cardiac catheterization laboratory, Circ Arrhythm Electrophysiol 7(1): 127-133.

8. Mori Y, Takahashi K, Nakanishi T (2013) Complications of cardiac catheterization in adults and children with congenital heart disease in the current era. Heart Vessels 28(3): 352-359.

9. Johnson JN, Marquardt ML, Ackerman MJ, Asirvatham SJ, Reeder GS, et al. (2011) Electrocardiographic changes and arrhythmias following percutaneous atrial septal defect and patent foramen ovale device closure. Catheter Cardiovasc Interv 78(2): 254-261.

10. Al Anani SJ, Weber H, Hijazi ZM (2010) Atrioventricular block after transcatheter ASD closure using the Amplatzer septal occluder: risk factors and recommendations. Catheter Cardiovasc Interv 75(5): 767772 .

11. Verheij G, Smits Wintjens V, Rozendaal L, Blom N, Walther F, et al. (2009) Cardiac arrhythmias associated with umbilical venous catheterisation in neonates. BMJ Case Rep doi: 10.1136/bcr.04.2009.1778.

12. Szkutnik M, Lenarczyk A, Kusa J, Białkowski J (2008) Symptomatic tachy-and bradyarrhythmias after transcatheter closure of interatrial communications with Amplatzer devices. Cardiol J 15(6): 510-516.

13. Xie YM, Zhang ZW, Li YF, Qian MY, Wang HS (2005) Management of the arrhythmia around the procedure of transcatheter closure of ventricular septal defects in pediatric patients. Zhonghua Xin Xue Guan Bing Za Zhi 33(12): 1092-1094. 
Your next submission with Juniper Publishers will reach you the below assets

- Quality Editorial service

- Swift Peer Review

- Reprints availability

- E-prints Service

- Manuscript Podcast for convenient understanding

- Global attainment for your research

- Manuscript accessibility in different formats

( Pdf, E-pub, Full Text, Audio)

- Unceasing customer service

Track the below URL for one-step submission https://juniperpublishers.com/online-submission.php 